\title{
Neuroectodermal-endocrine syndrome
}

INSERM

\section{Source}

INSERM. (1999). Orphanet: an online rare disease and orphan drug data base.

Neuroectodermal-endocrine syndrome. ORPHA:2676

Neuroectodermal-endocrine syndrome is characterised by a combination of endocrine and neuroectodermal abnormalities, including low growth hormone levels, delayed puberty, type II diabetes mellitus, mild intellectual deficit, sensorineural deafness, characteristic facial appearance and alopecia. It has been described in four sibs from Myanmar. 